American Journal of Applied Sciences 6 (5): 964-969, 2009

ISSN 1546-9239

(C) 2009 Science Publications

\title{
An Electrochemical Investigation of the Redox Properties of Murexide in Aqueous and Non-Aqueous Media
}

\author{
Hossnia S. Mohran \\ Department of Chemistry, Faculty of Science, Sohag University, Egypt
}

\begin{abstract}
Knowledge of solvent effects on the redox properties of Murexide (Mu) is important for understanding its role as an electron acceptor in analytical and inorganic chemistry. In the present study, an investigation of the electrochemical behavior of the compound by both Cyclic Voltammetry (CV) and Electrochemical Impedance Spectroscopy (EIS) in both aqueous and non-aqueous solutions was undertaken. It is suggested that, the reaction mechanism proceeds according to an Erev CE-revroute. This reaction mechanism is confirmed by the $\mathrm{CV}$ behavior for barbituric acid, which is essentially represent a main part of murexide, under the same conditions. In DMSO, the one-electron reduction potential peak of murexide was found to shift positively by $223 \mathrm{mV}$ to the value of the corresponding wave obtained in DMF under the same conditions. The shift is most readily explained by the presence of murexide aggregates in DMF. The one-electron oxidation potential position is relatively unaffected by aggregation. The data has also revealed that murexide decomposes in the level of radical anion at the $\mathrm{N}=\mathrm{C}$ bond into two approximately equal units. In aqueous sodium perchlorate $\left(\mathrm{NaClO}_{4}\right)$ solutions, it is suggested that the decomposion of murexide is relatively slow, leading to nearly a reversible 1e-transfer process (E-mechanism). In both $\mathrm{KNO}_{3}$ and $\mathrm{KCl}$ solutions, the oneelectron transfer step of murexide was found to be an adsorption wave. The Electrochemical Impedance (EIS) response of murexide is either low-frequency Warburg impedance or a capacitive semicircle behavior at high frequencies, depending on the medium.
\end{abstract}

Key words: Murexide-cyclic voltammetry (CV)-electrochemical impedance spectroscopy (EIS)-redox

\section{INTRODUCTION}

Murexide is the ammonium salt of purpuric acidand it is of inerest because it was probably the first metal ion indicator to be employed in the EDTA titration. The dye color changes are probably due to the displacement of protons from the imido groups; since there are four such groups. Murexide forms complexes with many metal ions: only those with $\mathrm{Cu}, \mathrm{Ni}, \mathrm{Co}, \mathrm{Ca}$ and the lanthanoides are sufficiently stable to find application in analysis. Aqueous solutions of murexide are unstable and must be prepared each day ${ }^{[1]}$.

The murexide $\left(5,5^{\prime}\right.$-nitrilodebarbituric acid, mono ammonium salt) in addition to its classical use as a metallochromic indicator, it has been employed is an efficient scavenger for superoxide and hydroxyl radicals ${ }^{[2]}$ and recently as a chromogenic agent ${ }^{[3]}$.

The electrochemical reduction mechanism of murexide complex with dysprosium has been studied by means of cyclic voltammetry and UV-vis spectroelectrochemistry at a gold minigrid optically transparent thin-layer electrode (OTTLE) cell. The electrode reaction rate constant was estimated and the formal potential and the electron transfer number at different $\mathrm{pH}$-values during the electrochemical process were measured ${ }^{[4]}$.

Murexide underwent reduction by rat liver cytosolic fraction or a hypoxanthine-xanthine oxidase system to produce a free radical metapolite. Reduction of murexide by the freshly prepared cytosolic fraction depended upon the presence of ascorbic acid ${ }^{[5]}$.

In all these treatments, little or no attention is given to the electrochemical behavior of murexide. Therefore, the interest was to use the cyclic voltammetric technique to shed some light on the effect of solvent on the electrochemical behavior of the compound in both aprotic and aqueous media.

\section{MATERIALS AND METHODS}

Reagent-grade N, N-Dimethylformamide (DMF) and Dimethyl Sulfoxide (DMSO) were further purified and dried according to a previous recommended $\operatorname{method}^{[6]}$.

Corresponding Author: Hossnia S. Mohran,Department of Chemistry, Faculty of Science, Sohag University, Egypt 
Tetrabutylammonium hexaflourophosphate $\left(\mathrm{TBAPF}_{6}\right)$ obtained from FLUKA was recrystallized twice from pure ethanol and vacuum dried at $120^{\circ} \mathrm{C}$. For sample preparation and purification for electrochemical measurements in super dry media, special type of cell was used which already described elsewhere $^{[7]}$. In this cell, three electrodes are used; the working is either a Platinum Disk $(\mathrm{Pt})$ or a metrohm EA 290 Hanging Mercury Drop Electrode (HMDE). A platinum wire is used as an auxiliary electrode. The reference electrode used is an $\mathrm{Ag} / \mathrm{AgCl}$ where its potential is calibrated for each experiment against the reversible oxidation peak of ferrocene. Aqueous electrolytes have been prepared using also reagentgrade chemicals and were diluted to proper concentrations with bidistilled water. The Saturated Calomel Electrode (SCE) was used in aqueous media as the reference electrode. An EG and G Princeton Applied Research 273A Potentiostat/Galvanostat coupled with an 5208 lock in amplifier were used to perform the desired signals.<smiles>Nc1nc(O)nc(O)c1N=C1C(O)=NC(OCCOC2NC(=O)C(N=C3C(=O)NC(=O)NC3=O)=C([OH2+])N2)=NC1O</smiles>

\section{RESULTS AND DISCUSSION}

CV behavior of murexide: The main features of the cyclic voltammogram for murexide in DMF containing $0.2 \mathrm{M} \mathrm{TBAPF}_{6}$ on the Pt-disk electrode are an irreversible peak at Epc $=-0.750 \mathrm{~V}$ followed by a small peak at $-1.0 \mathrm{~V}$ and a reversible process at more negative potentials, $\mathrm{Epc}=-1.448 \mathrm{~V}$ vs. $\mathrm{Ag} / \mathrm{AgCl}$. The main difference between the response in DMF and DMSO is that the potential position of the 1e-charge transfer process. In DMF, the wave was found to shift positively by $223 \mathrm{mV}$ to the value of the corresponding process in DMSO ( - $0.973 \mathrm{~V})$. The shift is most explained by the presence of murexide aggregates in $\mathrm{DMF}^{[8]}$. In DMF also, the first peak remains irreversible at all sweep rates less than $20 \mathrm{~V} / \mathrm{s}$ even if the scan is reversed at -1.2 $\mathrm{V}$ (i.e. before the second reversible peak) and its current function $\left(\mathrm{i}_{\mathrm{pc}} / v^{1 / 2} \mathrm{C}\right)$ does not vary significantly with potential scan rate.

On increasing the potential scan rate, the small peak at $-1.0 \mathrm{~V}$ observed in DMF is totally disappeared and the currents of the couple anodic peak at $-1.445 \mathrm{~V}$ become gradually smaller. It is suggested that the reduction mechanism proposed in this case is $\mathrm{E}_{\mathrm{rev}} \mathrm{CE}_{\mathrm{rev}^{-}}$ route. It is also assumed that the first wave corresponds to the reduction of murexide through a reversible 1etransfer process followed by a N-C bond-rupture, leading to two approximately identical parts. Two

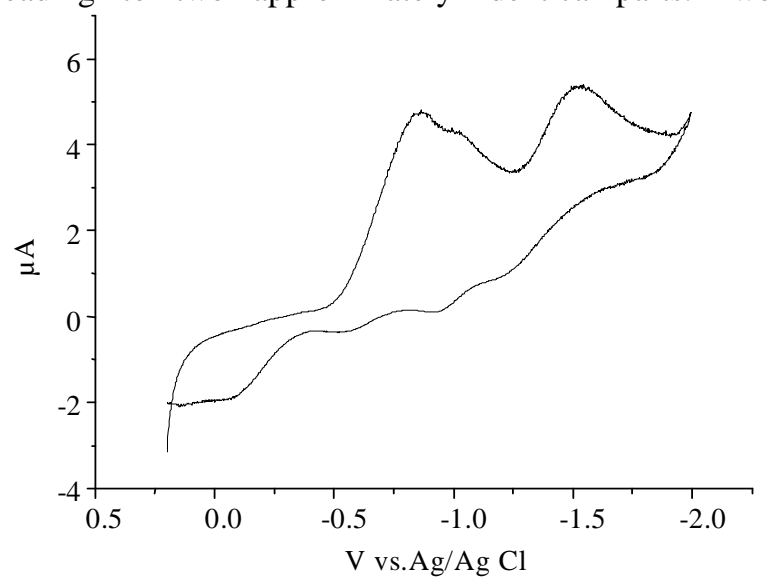

Fig. 1: CV diagram of $2.0 \mathrm{mM}$ of murexid in $\mathrm{DMF}^{\mathrm{TBAPF}} 6$ at $298 \mathrm{k}$ on the pt-disk electrode $(\mathrm{v}=0.05 \mathrm{v} / \mathrm{s})$

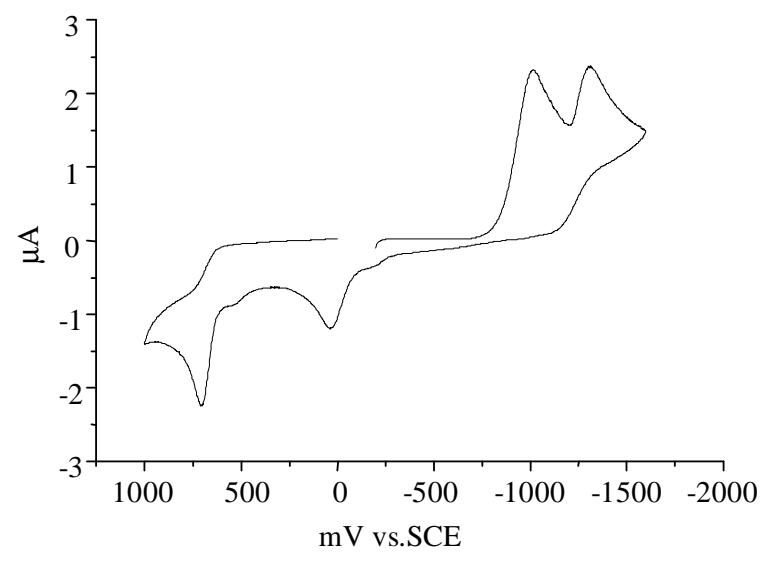

Fig. 2: CV of $1.32 \mathrm{mM}$ murexide in DMSO/0.2 M $\mathrm{TBAPF}_{6}$ on the Pt-Electrode at $298 \mathrm{~K}$ and scan rate of $0.1 \mathrm{~V} / \mathrm{s}$

further pieces of evidence confirm strongly the foregoing reaction mechanism. Firstly, the cyclic voltammograms for barbituric acid under the same conditions which were obtained in all media where measurements for murexide were carried out and under the same conditions. Secondly, if the potential scan rate for the electroreduction of murexide is increased to $1 \mathrm{~V} / \mathrm{s}$, fully reversible wave at $\mathrm{E}_{\mathrm{pc}}=-0.194 \mathrm{~V}$ is obtained and the small anodic peak at $\sim-0.018 \mathrm{~V}$ which is corresponding to the oxidation of the product of the follow-up chemical reaction is virtually disappeared. 
Fig.3a and Fig.3b represent examples for correlation between the electroreduction of both murexide and barbituric acid respectively. Barbituric acid must represent an essential part of murexide and is expected

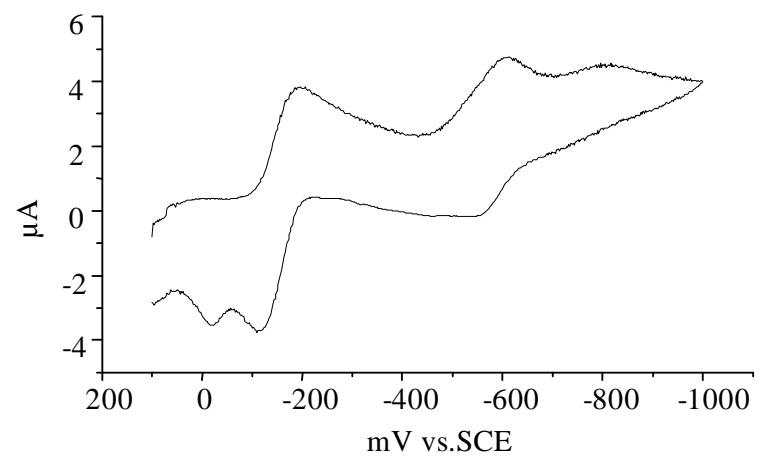

Fig. 3a: $\mathrm{CV}$ of $6.6 \mathrm{mM}$ murexide in $0.2 \mathrm{M} \mathrm{NaClO}_{4}$ on the $[\mathrm{HDME}]$ at $298 \mathrm{~K}$ and scan rate $=0.2 \mathrm{~V} / \mathrm{s}$

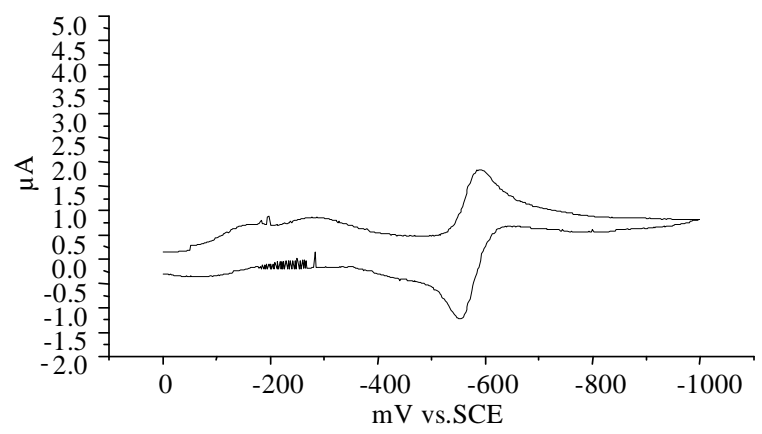

Fig. 3b: $5.0 \mathrm{mM}$ DEBA in $0.2 \mathrm{M} \mathrm{NaClO}_{4}$ on the [HDME] at $298 \mathrm{~K}$ and scan rate $=0.2 \mathrm{~V} / \mathrm{s}$

to be a main of the decomposion products of the molecule.

From the variation of $\mathrm{I}_{\mathrm{pa}} / \mathrm{I}_{\mathrm{pc}}$ for murexide/murexide radical anion couple at the faster sweep rates, it is possible to estimate the values, $4.0 \mathrm{~s}^{-1}$ and $6.0 \mathrm{~s}^{-1}$ for the homogeneous rate-constant for the $\mathrm{N}-\mathrm{C}$ bond-rupture of murexide in DMF and DMSO respectively. On the other hand, the electroreduction voltammogram of murexide in aqueous $\mathrm{NaClO}_{4}$ is obviously different and consists mainly of two consecutive reversible waves in addition to a small oxidation peak at $\sim 0.0 \mathrm{~V}$ (Fig. 3a). In Both $\mathrm{KNO}_{3}$ and $\mathrm{KCl}$ solutions, at relatively low concentrations of murexide, the voltammogram consists of an adsorption wave at the potential-position of the first wave. Fig. 4 shows the electrochemical behavior of $2.64 \mathrm{mM}$ of murexide in $\mathrm{KNO}_{3}$ solution at the [HMDE]. The cyclic voltammogram for murexide exhibits another reversible peak similar to that obtained in DMF or DMSO at $-1.445 \mathrm{~V}$. It is suggested that this wave represents the electroreduction of the known electrochemically stable structure of quinone functionalities part, which is similar to structure II resulting from decomposing murexide through the following-up chemical reaction and/or the medium. The voltammogram for barbituric acid, which is assumed to be half of the product after decomposing murexide, shows a well-defined $1 \mathrm{e}^{-}$reversible process at $\mathrm{E}_{\mathrm{pc}}=-$ $0.588 \mathrm{~V}$ in $\mathrm{NaClO}_{4}$ (Fig.3b), which is corresponding to the foregoing suggestion.

The CV-response of murexide in DMF in the presence of low concentration of bidistilled water (less than $2 \%$ ), shows that water increases the currents of both the cathodic and the anodic currents of the first electron reduction-wave. In addition to the increase of its chemical reversibility, appearance of a postpeak at $1.07 \mathrm{~V}$ is observed. This small wave is suggested to correspond to the reduction of the adsorbed species of murexide. The response of murexide in the presence of small amounts of water, reveals that the redox reactions of the molecule are also proton dependant.

In aqueous media $\left(\mathrm{KNO}_{3}\right.$ and $\left.\mathrm{KCl}\right)$ and at the beginning of measurements, the reduction behavior of low-concentrations of murexide is a simply an adsorption peak followed by a reversible electron transfer process. The peak-separation $\Delta \mathrm{E}$ for this wave is slightly less than $59 \mathrm{mV}$ and the $\mathrm{i}_{\mathrm{pa}} / \mathrm{i}_{\mathrm{pc}}$ is also slightly greater than unity, which are indicative of a weak adsorption of the reduction product of murexide ${ }^{[9]}$.

The cyclic voltammogram of the adsorption wave obtained in Fig. 4. was checked for symmetry around the peak potential using diagnostic criteria suggested for adsorption behavior ${ }^{[9]}$. At concentrations of murexide as low as $0.4 \mathrm{mM}$, the $\mathrm{CV}$ diagram exhibits an ideal symmetrical shape. On the other hand, if the concentration of murexide exceeds $2.0 \mathrm{mM}$ in $\mathrm{KNO}_{3}$ and $0.8 \mathrm{mM}$ in $\mathrm{KCl}$, the symmetry of the peak is nearly disappeared. At relatively higher concentrations of murexide, the current function at $\mathrm{v}=0.1 \mathrm{~V} / \mathrm{s}$ deviates from the constant value expected for diffusion peak uncomplicated by adsorption. This can be attributed to that the adsorbed molecules constitute a constant flow of matter and charge, whereas the number of the diffusing molecules through the electric double layer is potential scan-rate dependent (i.e. time dependent).

The $\mathrm{CV}$-adsorption behavior of the compound in $0.3 \mathrm{M} \mathrm{KNO}_{3}$ solutions at the [HMDE]. On plotting the current function $\left(\mathrm{i}_{\mathrm{p}} / \mathrm{C}_{\mathrm{o}}^{*} \cdot \mathrm{v}^{1 / 2}\right)$ vs. $\log \mathrm{v}$, where $\mathrm{C}_{\mathrm{o}}^{*}=$ the concentration of murexide and $\mathrm{v}$ is the potential scan rate, an increase in the sweep rate led to an increase in the current-function value. This behavior would be expected for a weak adsorption process. For an ideal $\mathrm{CV}$-reversible adsorption peak, the peak width at half- 
height of its current is $90.6 / \mathrm{n} \mathrm{mV}$ at $298 \mathrm{~K}^{[10]}$. The calculated peak-width value for the adsorption peak located in the forward scan of $1.88 \mathrm{mM}$ murexide in 0.3 $\mathrm{M} \mathrm{KNO}_{3}$ (Fig. 4) is found $101 \mathrm{mV}$, which agree well

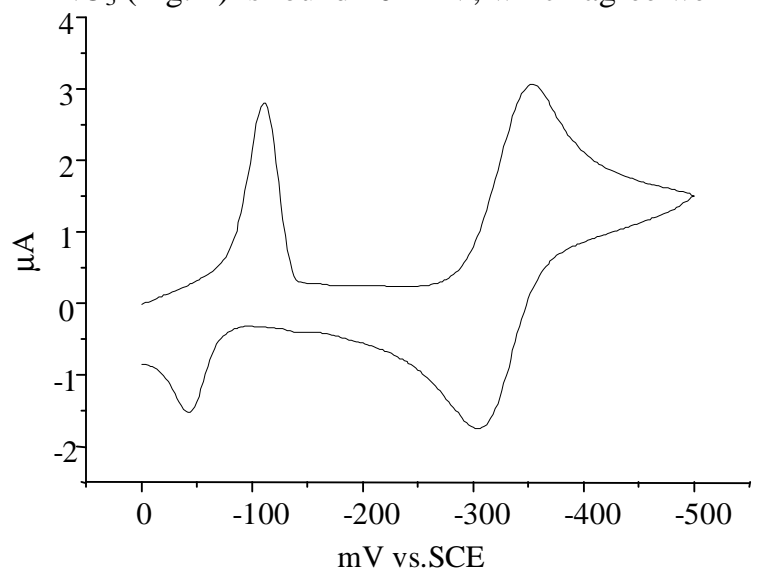

Fig. 4: $\mathrm{CV}$ for $2.64 \mathrm{mM}$ of murexide in $0.2 \mathrm{M} \mathrm{KNO}_{4}$ on $[\mathrm{HMDE}]$ at $298 \mathrm{~K}$,scan rate $=0.05 \mathrm{~V} / \mathrm{s}$

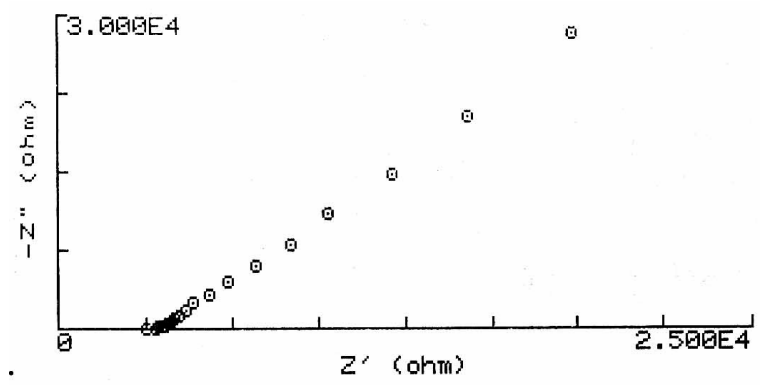

Fig. 5: Complex impedance plane plot (Nyquist) of the prewave of $3.43 \mathrm{mM}$ of murexide in DMF/0.2 M $\mathrm{TBAPF}_{6}$ on the Pt-electrode at $25^{\circ} \mathrm{C}$

with the reversible theoretical value of 1e-transfer process. The amount of adsorbed murexide on the [HMDE] is determined from the area of the cathodic peak which is expressed as surface concentration through the equation $\mathrm{A}(\mathrm{ad})=\mathrm{nFA}$, where $\mathrm{A}(\mathrm{ad})$ is the peak area, which in this case is $94.28 \mathrm{nC}$, A is the electrode surface-area and $\Gamma$ is the surface excess.

Impedance spectroscopic behavior of murexid: Figure 5 presents the Nyquist plot of the first reductionwave at $-0.374 \mathrm{~V}$ for $2.0 \mathrm{mM}$ of murexide in DMF/0.2 $\mathrm{M} \mathrm{TBAPF}_{6}$ at the $\mathrm{CV}$-peak potential on the Pt-disc electrode at $298 \mathrm{~K}$. The data demonstrates over the whole frequency range used, a linear impedance locus with an angle of nearly $45^{\circ}$ to the real axis with a very small resolved semicircle. The results are indicative of a partially diffusion-controlled process at the electrode- electrolyte interface. It is also suggested that the reversibility of the process is combined with some adsorption of the reactant and/or the reduction product on the electrode surface. The physical model

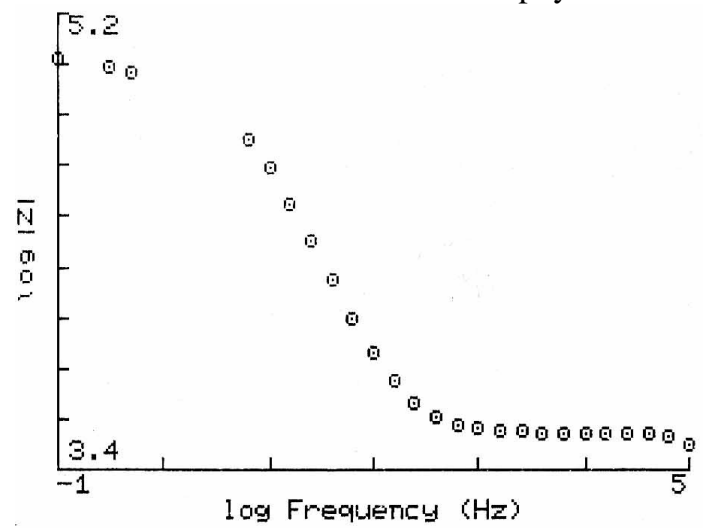

Fig. 6: The Bode magnitude plot of Complex impedance plane of $3.43 \mathrm{mM}$ of murexide in $\mathrm{DMF} / 0.2 \mathrm{M} \mathrm{TBAPF}_{6}$ on the Pt-electrode at $25^{\circ} \mathrm{C}$

appropriate to this case can be the simple equivalent Randle's electrical circuit ${ }^{[11]}$, which gives an evidence for the expected low-frequency Warburg response. Fig. 6 shows a typical Bode-magnitude plot for the same foregoing data of the peak at $-0.374 \mathrm{~V}$.

Changing the solvent from DMF to DMSO and keeping the same conditions, the Nyquist plot is a semicircle at high frequencies with a small straight linear behavior at sufficiently low frequencies. A behavior appears dominated by nondiffusional component, indicating that kinetics of the charge transfer step must be considered. Moreover, the data reveals nearly no evidence for adsorption processes in case of DMSO.

On the other hand, the EIS behavior of murexide in aqueous solutions $\left(0.2 \mathrm{M}\right.$ of each of $\mathrm{NaClO}_{4}, \mathrm{KNO}_{3}$ and $\mathrm{KCl})$ on the hanging mercury drop electrode [HMDE] is quite different than that obtained in DMSO or DMF. The response obviously consists of either one semicircle with a significant evidence for an adsorption contribution or two semicircles beside each other. In case of only one semicircle, adsorption behavior can be observed at very low frequencies especially with those measurements carried out in $\mathrm{KCl}$, where adsorptionphenomena is relatively significant. Another response for the impedance was the observation of two semicircles, a high-frequency semicircle (on the left) which is concluded to ascribe to bulk electrolyte properties and a low frequency one (on the right) which corresponds to the electrode polarization phenomena. 
The data, as concluded, are characteristic for a purely capacitive process. An ideal admittance plot for the electroreduction of $3.43 \mathrm{mM}$ of murexide in $0.2 \mathrm{M}$ $\mathrm{NaClO}_{4}$ on the [HMDE] at $298 \mathrm{~K}$ is presented in Fig. 7.

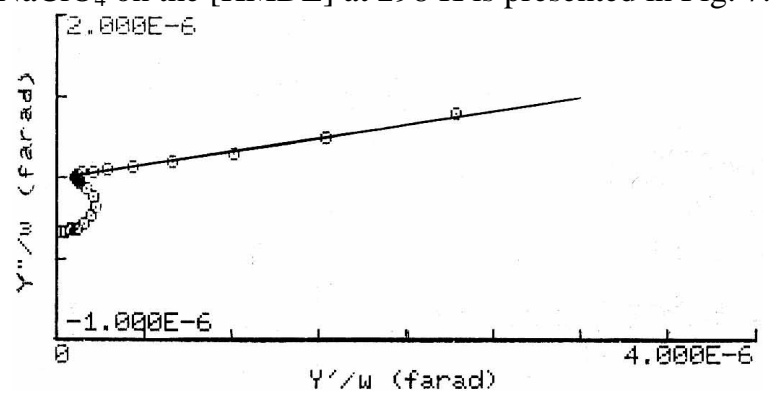

Fig. 7: An admittance plot of $3.43 \mathrm{mM}$ of murexide in $0.2 \mathrm{M} \mathrm{NaClO}_{4}$ on the $[\mathrm{HMDE}]$ at $25^{\circ} \mathrm{C}$

Table 1: Selected impedance Spectroscopic data for the electroreduction of murexide $(\mathrm{Mu})$ in aqueous and nonaqueous solutions on both the [HMDE] and the Pt-electrode respectively at $25^{\circ} \mathrm{C}$

\begin{tabular}{|c|c|c|c|}
\hline System & $\mathrm{R}_{\Omega}-\Omega$ & $\mathrm{R}_{\mathrm{c} \mathrm{\Omega}} \Omega$ & $\mathrm{C}_{\mathrm{dl}}$-Farad \\
\hline \multicolumn{4}{|l|}{ 1-Mu/DMF } \\
\hline $1 \mathrm{st}^{*}$ at $-0.374 \mathrm{~V}$ & 5652 & 21.40 & $8.30 \times 10^{-6}$ \\
\hline $2 \mathrm{nd} * *$ at $-0.650 \mathrm{~V}$ & 5623 & 11.40 & $3.90 \times 10^{-6}$ \\
\hline $3 \mathrm{rd}^{* *}$ at $-1.335 \mathrm{~V}$ & 5510 & 20.20 & $2.96 \times 10^{-6}$ \\
\hline \multicolumn{4}{|l|}{ 2-Mu/DMSO } \\
\hline $1 \mathrm{st} *$ at $-1.060 \mathrm{~V}$ & 6310 & 36.0 & $1.58 \times 10^{-6}$ \\
\hline $2 \mathrm{nd}^{* *}$ at $-1.310 \mathrm{~V}$ & 6310 & 79.4 & $1.43 \times 10^{-6}$ \\
\hline \multicolumn{4}{|l|}{ 3-Mu/NaClO 4} \\
\hline $1 \mathrm{st} *$ at $-0.200 \mathrm{~V}$ & 69 & 773 & $7.40 \times 10^{-6}$ \\
\hline $\begin{array}{l}\text { 2nd** at }-0.614 \mathrm{~V} \\
\mathbf{4 - M u / K C l}\end{array}$ & \multicolumn{2}{|c|}{ 4-Mu/KCl } & $4.65 \times 10^{-6}$ \\
\hline $1 \mathrm{st} *$ at $-0.105 \mathrm{~V}$ & 100 & 501.2 & $2.0 \times 10^{-5}$ \\
\hline $2 \mathrm{nd}^{* *}$ at $-0.330 \mathrm{~V}$ & 100 & 1000 & $1.0 \times 10^{-5}$ \\
\hline $3 \mathrm{rd}^{* *}$ at $-1.300 \mathrm{~V}$ & 100 & 5012 & $2.0 \times 10^{-6}$ \\
\hline
\end{tabular}

The figure gives a clearer picture of murexide admittance behavior and permits a convenient procedure for the determination of the system capacitance.

Table 1 provides a detailed compilation of the EIS parameters which resulted from application of these data treatment procedures. In aqueous solution, the values of the double-layer capacitance for the first charge transfer process fall in the range of $1 * 10^{-6} \mathrm{Farad}$, whereas those corresponding to the second charge transfer step are smaller by a factor of about 1.5. In DMF the $\mathrm{C}_{\mathrm{dl}}$ - values are larger than the corresponding values in aqueous medium by a factor of about 30-50. The table also includes the charge transfer resistance, which is of similar significance. The $\mathrm{R}_{\mathrm{ct}^{-}}$values, in aqueous perchlorate solution, are clearly larger than the corresponding values in aprotic medium by a factor of at least $\approx 30$, revealing the diffusion controlling character of the charge transfer processes in DMF as observed from $\mathrm{CV}$ results.

\section{CONCLUSION}

It is obvious from the data presented here that protic media clearly represent the best conditions for the mechanistic study of murexide. It is obviously that reversible behavior for the molecule is obtained more significant in aqueous than in non-aqueous solutions especially at the beginning of measurements. The difference can be accounted for by the greater basicity of DMF and DMSO compared to approximately neutral aqueous solutions used where murexide-decomposing is slower in the latter solutions. In $\mathrm{KNO}_{3}$, the oneelectron transfer peak-potential of murexide was found to shift positively by about $180 \mathrm{mV}$ than the corresponding wave in $\mathrm{NaClO}_{4}$ solution. It suggested that, adsorption of murexide and/or its reduction product have a significant effects on its redox potentials in both protic and aprotic solvents.

Minimizing the rate of the follow-up chemical reaction enhances the sensitivity of the measurements. It is also stated that, aqueous $\mathrm{NaClO}_{4}$ is more convenient than $\mathrm{KNO}_{3}$ and $\mathrm{KCl}$ solutions for both $\mathrm{CV}$ and EIS investigations of murexide.

As observed and suggested in this investigation, both murexide and its product of electron transfer are weakly adsorbed on the electrode surface especially the [HMDE] and the significance of adsorption is mediumdependent and is observed to follow the sequence:

$\mathrm{KCl}>\mathrm{KNO}_{3}>\mathrm{NaClO}_{4}>\mathrm{DMF}>\mathrm{DMSO}$.

\section{REFERENCES}

1. Bassett, J., R.C. Denney, G.H. Jeffery and J. Mendham, 1978. Vogel's Textbook of Quantitative Inorganic Analysis 4rth Edn., Longman Group Limited.

2. Torreilles, J., M.Ch. Guerin and M.L. Carrie, 1989. Murexide bleaching: A new direct assay method for characterizing reactive oxygen species. J. Biochem., 71: 1231-1234.

3. Akhlaghi, Y. and M.K. Zarch, 2005.Comparing radial basis function and feed forward neural networks assisted by linear discriminant or principal component analysis for simultaneous spectrophotom-metric quantification of mercury and copper. Anal. Chimica Acta., 537: 331-338.

4. Dong, S. and S. Song, 1987. Thin-layer spectroelectrochemical investigation on the electrode mechanism of murexide complex with dysprosium. J. Electroanal. Chem., 221: 143-153. 
5. Moreno, S.N.J. and R. Docampo, 1986. Reduction of the metallo-chromic indicators murexide and tetramethylmurexide to their free radical metabolites by cytoplasmic enzymes and reducing agents, Chem. Biol. Interactions, 57: 17-25.

6. Coetzee, J.F., 1982. Recommended methods for purification of solvents. Pergamon, Oxford.

7. Rashwan, F., 1988. Doctoral dissertation. ACvoltammetrische und cyclovoltammetrische Untersuchungen an mehrstufigen redoxsystemen. Freiburg i. Br. Universität, West Germany.

8. Katz, J.J., L.L. Shipman, T.M. Cotton and T.R. Janson, 1978. The Porphyrins. Acadmic Press: New York 5 part C pp: 401-458.
9. Wopschall, R.H. and I. Shain, 1967. Effects of adsorption of Electroactive species in stationary electrod polarograph. Anal. Chem., 39: 1514-1527.

10. Nicholson, R.S. and I. Shain, 1964. Theory of stationary electrode polarography: Single scan and cyclic methods applied to reversible, irreversibleand kinetic systems. Anal. Chem., 36: 706-23.

11. Macdonald, J.R., 1987. Impedance Spectroscopy. Emphasizing Solid Materials and Systems. Wiley and Sons, New York. 